\title{
MECANISMOS MULTIMODALES DE FOCALIZACIÓN DE LA INFORMACIÓN EN LA PRENSA DIGITAL DEL CAMPO CIENTÍFICO Y JURÍDICO: LA NEGRITA*
}

\author{
M. á Ángeles García Asensio, Fernando Polanco Martínez, Irene Yúfera Gómez \\ Universitat de Barcelona \\ Grupo EDAP (Estudios del Discurso Académico y Profesional) \\ garciaasensio@ub.edu; polanco@ub.edu; iyufera@ub.edu
}

Recibido: 02/09/2014

Aceptado: 03/06/2015

\begin{abstract}
Resumen
Para satisfacer el derecho a la información, la prensa digital recurre a cuatro sistemas semióticos (verbal, gráfico, matemático y tipográfico) con los que construye, organiza y jerarquiza contenidos y guía al lector en sus procesos interpretativos de la realidad periodística. La tipografía, intrínseca a la expresión verbal escrita, aporta su potencial de significado a través de sus rasgos distintivos y de dos principios semióticos: la connotación y la metáfora. En este artículo analizamos cómo la letra negrita, con su rasgo grosor de la letra, es usada en la prensa digital. Se analizan 60 noticias publicadas en España. Los periódicos digitales no coinciden en el tipo de segmento que resaltan en negrita. Hay también inconsistencias. Con todo, la negrita satisface en los textos periodísticos las tres metafunciones propuestas por Halliday (1978): ideacional, interpersonal y textual, a través de la macrofunción de resalte.

PALABRAS CLAVE: multimodalidad, prensa digital, tipografía, negrita, metafunciones.
\end{abstract}

\begin{abstract}
To satisfy the right to information, the digital press combines four semiotic systems (verbal, graphic, mathematical and typographical) to build and organize news content and to guide readers to understand and interpret the journalistic reality. Typography, visual appearance and potential meaningful aspect of the written verbal expression, brings its meaning potential through its distinctive features and, also, through two semiotic principles: connotation and metaphor. In this paper we analyze how bold typeface, with its characteristic heavy weight and thickness of the letter, is used in the digital press. 60 news items published in Spain are analyzed: digital newspapers do not agree on the kind of fragment highlighted in bold. There is also inconsistencies. Yet the bold typeface is used in journalistic texts to convey the three metafunctions proposed by Halliday (1978): ideational, interpersonal and textual, through the macrofunction of salience.

KEYWORDS: multimodality, digital media, typography, bold, metafunctions
\end{abstract}

\section{Introducción}

Dado el entorno multimodal, interactivo, intertextual e hipertextual (Pajares, 2004; Salaverría y Sancho, 2007; Cassany, 2011: 30-34) de la prensa digital, es esperable que hoy

\footnotetext{
* Este trabajo se enmarca en el proyecto de investigación Estrategias de textualidad del discurso profesional en sorportes multimodales. Análisis y propuestas de mejora (FFI2011-28933), financiado por el Ministerio de Economía y Competitividad.
} 
los periodistas recurran a estrategias propias del soporte digital para divulgar con rigor y claridad contenidos complejos. Algunos de estos contenidos atañen a campos de especialidad como el científico y el jurídico. El periodista que se introduce en estos campos debe manejar conceptos relacionados con la ciencia y con la justicia que se expresan con lenguajes especializados. Para acercar al público a estos lenguajes y satisfacer su derecho a ser informado verazmente, se hace necesario desplegar mecanismos de clarificación de contenidos indefectiblemente ligados a un léxico terminológico (Yúfera, García y Polanco, 2014). También el periodista ha de organizar y jerarquizar el contenido que maneja en el espacio visual de la pantalla y ha de guiar al lector en sus procesos interpretativos a fin de diferenciar los aportes de información jerárquicamente más relevantes para la comprensión global de la pieza informativa, enfatizarlos y convertirlos en foco informativo.

En la perspectiva metodológica que ofrece el análisis del discurso y el análisis del discurso multimodal desarrollado desde la semiótica social (Kress y Van Leeuwen, 1992, 1996, 2001), en este trabajo estudiamos hasta qué punto uno de los modos semióticos que opera en la prensa digital generalista funciona como mecanismo argumentativo para conferir relevancia informativa y enfatizar información sobre la actualidad científica y jurídica. Este modo, de uso habitual en la escritura digital, es a la vez un elemento visual y un recurso semiótico con un potencial de significado propio (Van Leeuwen, 2006; Serafini y Clausen, 2012: 2528). Se trata del modo tipográfico. Concretamente, en este trabajo nos interesamos por uno de los rasgos tipográficos que más realce adquiere en la escritura en la pantalla: la negrita.

\section{El potencial de significado de la tipografía en la perspectiva del análisis multimodal}

La caracterización lingüística de los mecanismos de construcción textual de los discursos que se generan en entornos digitales no puede obviar una aproximación a estos discursos en una perspectiva multimodal que supera lo estrictamente verbal. Efectivamente, en la red es ya difícil que un texto carezca de una combinación sinérgica de discurso escrito con otros modos semióticos.

Se entiende por modo (Kress y Van Leeuwen, 1996, 2001) -modalidad o sistema semiótico (Parodi, 2010)- cualquier recurso, vía, medio o material disponible en el contexto comunicativo, que se emplee con el propósito de crear significado(s) (Kress, Leite-García y Van Leeuwen, 2000: 377-383). Todo modo o sistema semiótico está constituido por un repertorio de signos de una misma naturaleza (verbal, gráfica, matemática, etc.) y un tipo de sintaxis articulada por principios de organización funcional, semántica o morfológica que regulan su disposición y su uso del espacio dentro del texto (Parodi, 2010).

De esta forma, en un entorno digital, imágenes fijas, vídeos u otros artefactos multisemióticos (Jewit, 2009) como las infografías, que originan mapas, gráficos, esquemas o viñetas, etc., se conjugan con el sistema verbal para crear significados completos, semánticos y pragmáticos, y servir a unas determinadas intencionalidades comunicativas dentro de un contexto sociocultural determinado. La escritura digital es una forma de comunicación de naturaleza multisemiótica o, si se prefiere, multimodal (Jewit, 2009).

Concretamente, Van Leeuwen (2006), O’Halloran (2008) o Parodi (2010) subrayan la existencia de cuatro sistemas semióticos que interactúan en los textos escritos y originan múltiples artefactos multimodales: el sistema verbal, el gráfico, el matemático y el tipográfico. Estos sistemas no solo establecen relaciones intrasemióticas -hacia el interior de su 
sistema-; también sus relaciones son intersemióticas -entre sistemas-, según los significados que en cada momento se quieran expresar.

Forman el sistema verbal palabras, cláusulas y oraciones que construyen significados basados en lo lingüístico. El sistema gráfico se constituye a partir de trazos que conforman una representación pictórica y que permiten presentar datos en formatos distintos, normalmente combinando varios modos: fotografías, gráficos, diagramas, tablas, etc. El sistema matemático acoge grupos de grafías, signos o representaciones que permiten codificar significados de forma sintética: números romanos o árabes, letras griegas o latinas, operadores y signos de puntuación. El sistema tipográfico se presenta inseparable de los sistemas verbal, gráfico o matemático, y, de hecho, es intrínseco a la expresión verbal escrita: es la apariencia visual del sistema verbal. La introducción de los procesadores de texto ha sido el detonante que ha puesto de manifiesto el potencial de significado de las formas y de los colores de las letras: negritas, cursivas, mayúsculas, bajas (minúsculas), así como de su dimensión tipográfica uni, bi o tridimensional (Van Leeuwen, 2005a, 2006; Machin, 2007: 83-108; Norgaard, 2009; Parodi, 2010).

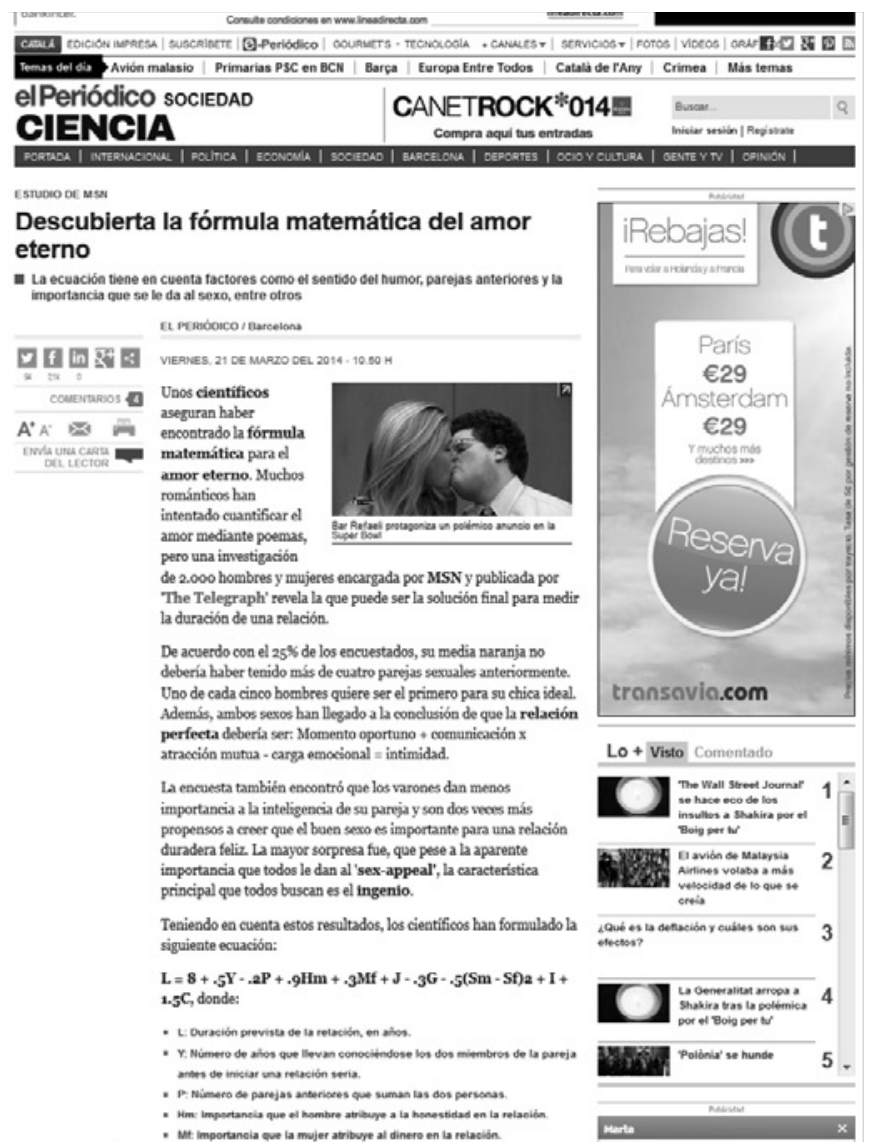

Figura 1. Modos semióticos en una crónica digital. Fuente: El periódico (Edición digital. 21/03/2014) 
En la figura 1 puede apreciarse cómo los distintos sistemas semióticos ocupan una posición en la arquitectura del espacio visual (layout) e interactúan en la construcción del significado global de una crónica científica publicada en la sección de Sociedad. Ciencia de la edición digital de El Periódico.

Así, teniendo en cuenta que el layout también aporta una carga de significado (Van Leeuwen, 2006: 139-141), en la muestra textual se observa cómo todos los modos (verbal, gráfico, matemático y tipográfico) interactúan en el cuerpo del relato periodístico, cuerpo que, a su vez, ocupa la columna central del espacio visual de la página. De este modo, de acuerdo con la semiótica social del espacio visual (Kress, Leite García, Van Leeuwen, 2000: 404-406), este espacio central, más ancho, pone de manifiesto la relevancia informativa, de densidad transaccional, del cuerpo del relato respecto de los aportes de información paratextual, que se ubican en los márgenes derecho e izquierdo de la arquitectura del espacio web. También en estos espacios marginales actúan los cuatro sistemas semióticos.

Se observa, además, cómo la fotografía de mayor tamaño (sistema gráfico) y su pie (sistema verbal y tipográfico) se ubican, también a su vez, en una relación con el texto del cuerpo de relato, de información conocida (texto del relato) a información nueva (fotografía y pie) (Kress y Van Leeuwen, 1996: 186-192): su ubicación en el margen superior del cuerpo del relato es, asimismo, significativa, pues es en este espacio donde se despliegan estrategias conducentes a llamar la atención sobre el propio texto y a mantener abierto el canal de interacción con el lector (espacio para fotografías, vídeos, entradilla).

Finalmente, la cabecera (Sociedad. Ciencia) y el encabezamiento (titulares) ocupan el margen superior de la página, al que forzosamente se le asocia la significación de satisfacer una función identificativa (García y Palomeque, 2012): los modos verbal y tipográfico son en este espacio superior altamente relevantes para satisfacer esta función identificativa, a la vez que de llamada de atención. El distinto tamaño de la fuente señala una mayor jerarquía informativa respecto del cuerpo del relato, dado que en los titulares se identifica el tema dominante de cada noticia y se anticipan otros contenidos relevantes, según las mediaciones cognitivas y la postura ideológica del medio. De esta manera se guía al lector en su proceso de interpretación de la información y en el establecimiento de la macroestructura semántica y de la coherencia global de cada relato periodístico (Van Dijk, 1998: 59).

Ahondando en el sistema tipográfico, al que la prensa escrita y la digital prestan una atención creciente (Machin, 2007: 83), fue Kress (2003) quien planteó considerarlo como un modo más, lejos de considerarlo como un mero elemento estético o únicamente como un rasgo que atañe a la legibilidad de un texto y que, por tanto, facilita o dificulta su lectura y su procesamiento (Serafini y Clausen, 2012). De hecho, hasta entonces las investigaciones lingüísticas realizadas en una perspectiva multimodal habían descuidado este modo. Van Leeuwen $(2005 \mathrm{a}, 2006)$ impulsa estas investigaciones y reivindica su estatuto de modo semiótico con entidad propia. Machin (2007), Norgaard (2009) o Serafini y Clausen (2012) subrayan su papel esencial en los procesos comunicativos.

Más aún, las investigaciones de Van Leeuwen (2006) pretenden indagar en la gramática de la tipografía, para lo que proponen una primera sistematización de sus rasgos distintivos y no distintivos (Van Leeuwen, 2006: 147-152). La enumeración de estos rasgos incluye el grosor del tipo de letra o fuente, su expansión, inclinación, curvatura, conexión, orientación respecto de la dimensión horizontal y regularidad, en tanto que rasgos distintivos; así como el trazo, el remate, las florituras o ligaduras, entre otros rasgos no distintivos. En Machin 
(2007) o en Norgaard (2009) se propone añadir a esta lista otros rasgos como la textura o el color, lo que implica, en este último caso, tener en cuenta la saturación cromática, la modulación, el contorno del texto, sombras, reflejos, bordes e iluminados, etc.

Junto con la sistematización de los rasgos tipográficos, dos son los principios semióticos clave propuestos por Kress y Van Leeuwen (2002) y por Van Leeuwen (2005a, 2005b) para explicar cómo estos rasgos, en el marco del modo tipográfico, aportan en un texto su potencial de significado: la connotación y la metáfora. El significado que potencialmente se construye a través de la connotación se origina de una importación discursiva de asociaciones desde el contexto al que pertenecía originalmente un tipo de letra al contexto en que esta letra es usada (Van Leeuwen, 2005a: 139), a fin de significar las ideas y los valores asociados al contexto de origen en el contexto de destino: una fuente Tivaldi puede evocar, por ejemplo, un tiempo en la historia en que la escritura era siempre manual, cuidada. Es un tiempo al que solemos asociar un ritmo vital más sosegado que el actual. La fuente Vivaldi puede connotar, pues, por asociación, valores de calma, sosiego, cuidado.

La metáfora tipográfica (Van Leeuwen, 2005b: 29-36; Van Leeuwen, 2006: 146-147) se basa, por su parte, en el principio de similitud entre la forma tipográfica, que es la forma visual del significante, y su significado. De este modo, una letra en negrita puede significar, metafóricamente $-\mathrm{o}$, si se prefiere, de acuerdo, también, con el concepto de icono desarrollado por Peirce (Norgaard, 2009: 147-154)- fuerza, solidez, asertividad: los objetos cotidianos de un grosor o de una anchura manifiesta suelen ser sólidos, fuertes, difíciles de romper ${ }^{1}$.

En cualquier caso, el proceso de decodificación del significado transmitido por un rasgo tipográfico implica siempre considerar su contexto y, por tanto, su interacción con otros significados aportados por otros elementos tipográficos o por otros sistemas que concurren simultáneamente en un sincretismo multimodal con tal rasgo tipográfico. El rasgo es un recurso con el que construir un significado. Su significado es potencial (Van Leeuwen, 2005a). En este sentido, para descodificar el significado de una negrita en una palabra de este modo destacada, deberá tenerse en cuenta el tamaño u otros rasgos tipográficos de las letras (la misma tipografía es multimodal); el propio significado léxico de la palabra destacada ${ }^{2}$, vehiculado por el sistema verbal; la presencia o no de comillas delimitadoras de cita enmarcando la palabra, etc. En este contexto, una negrita, portadora de un significado de aserción, fuerza o solidez, puede asimismo, por connotación, evocar un significado asociado de dogma o intransigencia y contribuir a dibujar, en un determinado texto, un personaje autoritario, inflexible o despiadado, que va a generar una actitud desvalorizante en el lector; o, al contrario, un personaje firme, estable e incluso audaz (Van Leeuwen, 2006: 148; Machin, 2007: 104).

Cabe, por último, especificar que el potencial de significado del sistema tipográfico ha de relacionarse con su potencial comunicativo. En Van Leeuwen (2006:142-143), Machin (2007: 89-92) o en Serafini y Clausen (2012: 28) se subraya que los rasgos tipográficos pueden, de hecho, satisfacer las tres metafunciones comunicativas descritas por Halliday (1978) en su teoría metafuncional sobre el lenguaje. De este modo, se sostiene que la tipografía puede usarse, pues, ideacionalmente, para representar el mundo y lo que en él ocurre, así

1 En Van Leeuwen (2006: 147-154) o en Machin (2007: 93-108) se ofrece un inventario de potenciales significados asociados a determinados rasgos tipográficos.

2 En Van Leeuwen (2006: 142) se cita a los diseñadores Bellantoni y Woolman (2000), que indican que la palabra escrita tiene dos niveles de significado: la 'word image'; es decir, la idea representada por la misma palabra, construida a partir de la cadena de letras, y la 'typographic image', la 'impresión visual holística'. 
como lo que ocurre en nuestras mentes (conceptos, cualidades y acciones); interpersonalmente, para representar y establecer relaciones sociales, y expresar las actitudes del emisor hacia lo representado; o textualmente, para organizar la estructura informativa de un texto, delimitar elementos textuales y crear vínculos cohesivos entre ellos o conferir mayor jerarquía informativa a determinados segmentos.

En definitiva, un contraste visual entre una tipografía regular y una tipografía marcada en un universo multimodal implicará siempre tanto diferencias de significado como diferencias funcionales.

\section{Las funciones comunicativas de la negrita}

El aumento de grosor de las letras es el rasgo tipográfico que caracteriza la letra negrita. La perspectiva de análisis multimodal vincula la tipografía a las metafunciones ideacional, interpersonal y textual, por lo que el uso de la negrita debe también relacionarse con estas metafunciones. No por ello cabe obviar que el recurso a la negrita se ha venido describiendo tradicionalmente en tanto que orientado al resalte de segmentos textuales y de contenidos $\mathrm{y}$, por tanto, a la focalización de la información. De hecho, tal vez haya que considerar que esta función de resalte es previa y ligada convencionalmente al uso de la negrita (Norgaard 2009: 150). Es significativo, al respecto, observar la definición que se ofrece para la entrada negrilla o negrita en el Diccionario de la lengua española (avance de la vigesimatercera edición) (RAE, 2001: s.v. negrilla) en su publicación en línea:

$\sim$ negrilla, o $\sim$ negrita.

1. f. letra gruesa que se destaca de los tipos ordinarios, resaltando en el texto.

Efectivamente, el aumento del grosor de la letra resalta el segmento de texto en negrita. Con este resalte, se llama la atención del lector sobre dicho elemento, que aumenta así su grado de prominencia (saliencia ${ }^{3}$ ) (Van Leeuwen, 2006: 148; Serafini y Clausen, 2012; 29) y cobra mayor relevancia en el contexto. El resultado es la generación de una expectativa acerca de su potencial importancia referencial y comunicativa.

En esta perspectiva, podría decirse, pues, que la negrita satisface en primer lugar y fundamentalmente una macrofunción de resalte informativo que crea una expectativa sobre la significatividad potencial de los elementos marcados. Es mediante este significado potencial como, en contexto, pueden satisfacerse las macrofunciones propuestas por Halliday (1978).

Creemos que es importante subrayar el concepto de significatividad potencial, en tanto que el hecho de resaltar un elemento informativo del texto no lo convierte necesariamente en una pieza relevante en el proceso interpretativo y comunicativo, sino solo en una pieza potencialmente relevante. En este sentido, ciertamente el elemento destacado en negrita llama la atención del lector y genera en él una determinada expectativa sobre su importancia contextual, expectativa que se verá cumplida si efectivamente este elemento supone un dato que aporte significatividad al texto. Con todo, pese a que esta interpretación se activa de forma automática, el significado de resalte informativo puede anularse contextualmente si, una vez centrada la atención sobre el elemento marcado, este

3 "Salience, making a given text element stand out from its immediate textual environment" (Van Leeuwen, 2006: 144). La saliencia o resalte se puede crear a través del color, el tamaño, el movimiento, una palabra o frase, etc. 
no cumple las expectativas generadas en el lector; esto es, si el resalte no se corresponde efectivamente con algún valor interpretable en ese sentido. Esto podría suceder si hay una sobremarcación de elementos informativos en el texto que impiden descubrir cuál es la finalidad perseguida por el escritor al seleccionar dichos elementos y, en definitiva, cuál es su relevancia contextual.

En definitiva, siendo el valor más prototípico de la negrita señalar la prominencia y, por tanto, la significatividad potencial de determinados elementos del texto, la negrita, se describe, entonces, efectivamente, como susceptible de satisfacer las tres metafunciones descritas por Halliday (1978). Así, podrá usarse para crear (i) significados ideacionales, mediante la connotación y la metáfora, como asertividad, solidez o fuerza, audacia; (ii) significados interpersonales relacionados con la actitud del emisor respecto del elemento marcado, que tratan de sugerir en el lector determinadas interpretaciones contextuales de carácter modal; y (iii) significados textuales asociados con la cohesión y la coherencia de los elementos informativos del texto. Estas interpretaciones, a diferencia del valor de resalte (saliencia), son mucho menos estables y dependen totalmente del contexto.

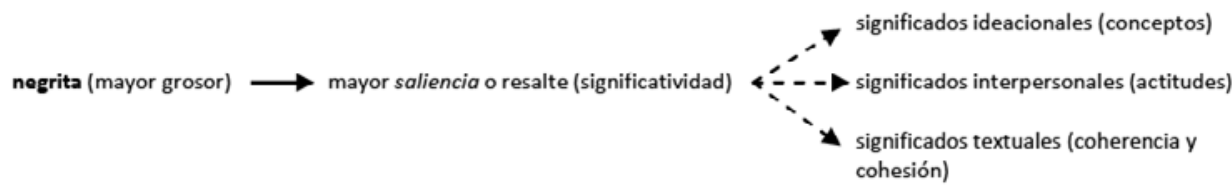

Figura 2. Esquema de las funciones comunicativas de la negrita.

La función de resalte (informativo) representa, pues, una función genérica o macrofunción que suele materializarse contextualmente en distintos usos más concretos que encajan dentro de alguna de las tres metafunciones comunicativas de Halliday (1978): ideacional, interpersonal y textual.

\section{Objetivos de la investigación}

Con el foco puesto en el periodismo digital, nos interesamos en este trabajo por determinar las metafunciones comunicativas que satisface la negrita en la redacción ciberperiodística en español, puesta al servicio de las necesidades comunicativas y de construcción textual de los periodistas. Estas necesidades vienen habitualmente regidas por el principio pragmático de conferir a los textos claridad, concisión y corrección (Martínez Albertos, 1997: 203).

Los teóricos del ciberperiodismo señalan a la negrita como la forma clásica de resaltar o destacar un texto (Palomo, 2005: 210), lo que corresponde a la macrofunción de saliencia o resalte, y alertan de las consecuencias de un abuso de este rasgo tipográfico para la legibilidad de los contenidos, especialmente cuando la negrita abarca un segmento demasiado extenso (Salaverría, 2006: 86; Steen, 2012: 298-299).

En Salaverría (2006: 86-87) o en Tascón (2012) se indican los usos que debería tener la negrita en la prensa digital: (i) señalar las palabras, secuencias léxicas o frases con fuerza argumentativa o carga significativa clave (sujetos protagonistas, núcleo informativo de la noticia), lo que implicará habitualmente resaltar nombres propios y términos especializados 
de diversa disciplinas científicas, médicas, judiciales; y (ii) derivado de este uso, facilitar que la noticia sea hallada por los motores de búsqueda a través de la etiqueta HTML $<$ strong $>$. Se apunta así a la metafunción textual, en tanto la negrita, con estos usos, contribuye a jerarquizar y a estructurar contenidos y facilita al lector el rápido rastreo de las ideas o argumentos principales de una noticia (lectura en skimming) o buscar una información específica (lectura en scanning).

Nuestro objetivo pretende confirmar los usos descritos por los teóricos del periodismo; pero no excluye documentar otras metafunciones (ideacional e interpersonal) y ahondar en la metafunción textual. Concretamente, dos son las preguntas de investigación que se derivan de este objetivo, sin que descartemos, en un análisis contrastivo, que las ediciones digitales de los distintos periódicos presenten diferencias en el uso de la negrita:

1. Desde un punto de vista formal: ¿qué segmentos textuales son resaltados en negrita?

2. Desde un punto de vista comunicativo: ¿la negrita satisface las tres metafunciones descritas para el sistema tipográfico?

\section{Metodología}

Fundamentamos el estudio en un análisis empírico y contrastivo de carácter cuanticualitativo realizado sobre un corpus compuesto por 60 noticias y crónicas publicadas en los principales periódicos españoles con edición digital: El País, La Vanguardia, Público, El Periódico, Abc y El Mundo ${ }^{4}$. De las piezas informativas que lo constituyen, 34 versan sobre asuntos legislativos y judiciales (J) y 26 son de contenido científico (C), como puede observarse en la siguiente tabla (tabla 1): el carácter especializado de los campos jurídico y científico puede favorecer el uso de la negrita para resaltar piezas léxicas que corresponden a términos de la especialidad, de acuerdo con lo señalado en Salaverría (2006: 86-87) y en Tascón (2012); de ahí que estos campos hayan sido objeto de nuestro interés.

\begin{tabular}{|c|c|c|c|c|c|c|c|}
\hline & El País & La Vanguardia & Público & El Periódico & $A B C$ & El Mundo \\
\hline \multirow{2}{*}{$\begin{array}{c}\mathbf{N}^{\mathbf{o}} \\
\text { crónicas }\end{array}$} & $\mathbf{J}$ & 7 & 5 & 7 & 5 & 5 & 5 \\
\hline & C & 6 & 4 & 4 & 4 & 5 & 3 \\
\hline \multicolumn{2}{|c|}{$\mathrm{N}^{0}$ textos } & 13 & 9 & 11 & 9 & 10 & 6 \\
\hline \multicolumn{2}{|c|}{$\begin{array}{l}\mathrm{N}^{0} \text { total en el } \\
\text { corpus }\end{array}$} & \multicolumn{6}{|c|}{$34 \mathrm{~J}+26 \mathrm{C}=60$} \\
\hline
\end{tabular}

Tabla 1. Número de piezas informativas según medio y campo temático.

En una primera fase de la investigación hemos identificado en el corpus los segmentos resaltados en negrita. De este modo, las noticias y crónicas estudiadas nos han proporcionado 227 segmentos resaltados en el cuerpo del texto. En este cómputo hemos desestimado los elementos destacados en negrita que no pertenecen al cuerpo textual del relato informativo: titulares, destacados, ladillos, pies de foto, entre otros. El cuerpo del relato es nuestro objeto

4 Las piezas forman parte de un corpus mayor constituido por noticias y crónicas publicadas entre diciembre de 2012 y marzo de 2014. 
fundamental de investigación. La distribución del total de segmentos considerados en el trabajo según el medio en que aparecen y el ámbito sobre el que versa la pieza informativa en que se hallan puede verse en la tabla que se incluye a continuación (tabla 2):

\begin{tabular}{|c|c|c|c|c|c|c|c|}
\hline \multicolumn{2}{|c|}{} & El País & La Vanguardia & Público & El Periódico & ABC & El Mundo \\
\hline \begin{tabular}{c}
$\mathbf{N}^{\mathbf{0}} \begin{array}{c}\text { segmentos } \\
\text { en negrita }\end{array}$ \\
\cline { 2 - 8 }
\end{tabular} & $\mathbf{J}$ & 0 & 28 & 26 & 26 & 30 & 62 \\
\hline $\begin{array}{c}\mathbf{N}^{\mathbf{0}} \text { total según } \\
\text { medio }\end{array}$ & $\mathbf{0}$ & $\mathbf{4 1}$ & $\mathbf{3 3}$ & $\mathbf{3 5}$ & $\mathbf{5 6}$ & $\mathbf{1 1}$ \\
\hline $\begin{array}{c}\mathbf{N}^{\mathbf{0}} \begin{array}{c}\text { total en el } \\
\text { corpus }\end{array} \\
\mathbf{y y y y y y y y}\end{array}$ & $\mathbf{1 6 1} \mathbf{~ J}+\mathbf{6 6} \mathbf{C}=\mathbf{2 2 7}$ \\
\hline
\end{tabular}

Tabla 2. Número de segmentos resaltados en negrita según medio y campo temático.

Con la finalidad de responder al objetivo y a las preguntas de investigación, el análisis de los segmentos en negrita documentados se ha organizado en dos fases: análisis de sus características formales, en primer lugar, que ha llevado a observar algunas inconsistencias; $y$, entonces, análisis de las funciones comunicativas. Los resultados se exponen a continuación.

\section{Resultados y discusión}

\subsection{Descripción formal}

El corpus analizado permite constatar que hay diferencias entre los distintos medios en cuanto al uso de la negrita. En las crónicas y noticias de El País, no se ha documentado el empleo de la negrita para realzar segmentos dentro del cuerpo del texto de las piezas informativas, si bien este recurso tipográfico se emplea, por ejemplo, en los despieces. En La Vanguardia, los segmentos en negrita se sitúan, mayoritariamente, en los dos primeros párrafos de los textos en que se desarrolla la información, y, junto con los de El Periódico, destacan, frente a los seleccionados en otros medios, por su brevedad: de promedio, constan de dos palabras. Además, las muestras de estos dos medios coinciden también en el hecho de tratarse en buena parte de elementos nominales y, con frecuencia, de nombres propios. Este empleo de la negrita parece responder, por lo tanto, en estos dos medios, a algunas decisiones tomadas al respecto en el consejo de redacción ${ }^{5}$. Así lo ilustran los siguientes ejemplos:

5 Estas decisiones no quedan recogidas en los libros de estilo de estos medios. De hecho, los libros de estilo de los periódicos que analizamos en este artículo todavía carecen de una reflexión exhaustiva y detallada acerca del uso concreto de la negrita en el cuerpo del texto de las piezas informativas en la edición digital, tanto en lo que atañe a la función comunicativa de la negrita como al alcance formal y a los límites de los segmentos destacados mediante esta tipografía. Los libros de estilo de $E l$ Mundo o de $A B C$ sí coinciden en señalar que, en el cuerpo de la pieza informativa, pueden marcarse en negrita los nombres propios que se desean destacar la primera vez que se citan, si bien en su edición digital el uso de la negrita supera esta indicación, según observamos en nuestro corpus de estudio y explicamos en este artículo: es, con todo, un uso recurrente que sí observamos en las piezas analizadas en nuestro trabajo procedentes de El Periódico o La Vanguardia. El manual de estilo de El Periódico no contempla, ni siquiera, en sus páginas ninguna reflexión sobre el uso de la negrita. 
(1) Barcelona. (Agencias). El fiscal Anticorrupción Pedro Horrach puede pedir hasta 17 años de prisión para el duque de Palma, Iñaki Urdangarin. En cambio, de no encausar a la Infanta, confirmando así una postura alejada de la mantenida en su imputación por el juez José Castro, Doña Cristina debería pagar un monto de 600.000 euros por responsabilidad civil.

Cuando se encara el tramo final del caso Nóos, y considerando los diferentes delitos de malversación, falsedad y otros fiscales que se juzgan en los juzgados de Palma de Mallorca, Horrach podría reclamar al Duque de Palma hasta 17 años de cárcel y considerar hasta 15 para su exsocio Diego Torres.

La Fiscalía considera un total de 132 años de cárcel para 16 de los 41 imputados en el caso Nóos, entre los que también se incluye al ex presidente Balear y ex ministro Jaume Matas. El Ministerio Fiscal no tendría intención de reclamar penas de prisión a Doña Cristina de seguir la postura mantenida hasta ahora, al igual que tampoco se incluiría a su secretario, Carlos García Revenga, ni tampoco a Ana María Tejeiro, la esposa de Torres.

En días anteriores se especuló igualmente con un pago de 600.000 euros que tendría que realizar la Infanta por responsabilidad civil como socia de Aizoon.

(La Vanguardia, http://www.lavanguardia.com/politica/20140210/54400110142/fiscaliacarcel-urdangarin.html)

(2) El juez José Castro ha imputado este martes a la infanta Cristina por delito fiscal y blanqueo de capitales en el 'caso Noos'. En un extenso auto de 227 folios, el titular del juzgado de instrucción número 3 de Palma concluye que hay indicios delictivos suficientes en el comportamiento de la hija del Rey y le cita a declarar el próximo 8 de marzo, a las 10 horas.

(El Periódico, http://www.elperiodico.com/es/noticias/politica/juez-castro-imputa-infantacristina-delito-fiscal-blanqueo-capitales-caso-noos-2988109)

Los criterios seguidos por los profesionales de Público, Abc y El Mundo respecto del uso de negritas, en cambio, resultan difíciles de identificar, pues las unidades realzadas pertenecen a categorías gramaticales muy variadas y se encuentran en cualquier lugar del texto. Cabe decir, no obstante, que tanto en $A b c$ como en $E l M u n d o$, es frecuente el realce de citas directas o de parte de ellas mediante negritas:

(3) Posteriormente, el 13 de marzo, el Parlament aprobó por una amplia mayoría, más de dos tercios de la Cámara (104 votos), una resolución en la que se instó al Gobierno de la Generalitat a «iniciar un diálogo» con el Ejecutivo central para celebrar una consulta de autodeterminación en Cataluña. Esta iniciativa fue votada a favor por CiU, ERC, ICVEUiA y PSC. http://www.abc.es/espana/20140214/abci-constitucional-catalua-201402140151.html)

(4) En su auto, el juez Castro insiste en cuestionar una y otra vez el argumento de que la Infanta Cristina desconocía las tareas y los negocios de su marido: "Presumir que quien supuestamente se ha lucrado de la manera anteriormente expuesta desconociera por completo de lo que se estaría hablando y que por ello no merecería la pena preguntarle no es de recibo". 
En cualquier caso, desde un punto de vista formal, el corpus de noticias y crónicas que hemos analizado contiene segmentos resaltados en negrita que pertenecen a categorías gramaticales muy variadas. La unidad mínima realzada mediante el recurso de la negrita es un nombre común. En este sentido, es frecuente que el periodista opte por no marcar en negrita el determinante que acompaña al sustantivo, como en el ejemplo (5):

(5) Irrumpir (sic) el embarazo volverá a dejar de ser un derecho, el Gobierno ha aprobado la ley del aborto más restrictiva de la democracia. De hecho, supone un retroceso de tres décadas, significa volver al año 1985.

El aborto solo será posible en dos casos: si se trata de una violación o si el embarazo supone un peligro para la salud física y psíquica de la mujer. En el mismo sentido, la presencia de malformaciones fetales no será motivo de aborto, sólo el efecto psicológico que suponga (sic) en la embarazada.

La reforma tendrá el nombre de Ley de Protección de la Vida Concebido (sic) y de los Derechos de la Mujer Embarazada, la cual ha sido creada, según el ministro de Justicia, Alberto Ruiz-Gallardón, para proteger "a los más débiles: los concebidos y no nacidos", aunque "siempre en interés de la mujer".

(El Periódico, http://www.elperiodico.com/es/noticias/sucesos-y-tribunales/nueva-ley-supone-retroceso-tresdecadas-2948349)

Numerosos son asimismo en el corpus los nombres propios en negrita, correspondientes a personas que protagonizan una determinada noticia, como en el ejemplo (6) o a organismos (National Ignition Facility (NIF)), instituciones, leyes, publicaciones o, como en (7), a instrumentos científicos como cohetes, sondas, naves o satélites.

(6) Barcelona. (EFE).-Mario Pascual Vives, el abogado de Iñaki Urdangarin, ha evitado hoy pronunciarse sobre la posible petición del fiscal para el duque de Palma -que según algunas informaciones podría ascender hasta los 19 años de cárcel- alegando que no se fía de nada hasta que lo vea por escrito.

(La Vanguardia, http://www.lavanguardia.com/politica/20140211/54401050543/abogadourdangarin-desconfia-posible-peticion-fiscal.html)

(7) La sonda Planck, lanzada en 2009, continúa surcando el espacio.

(Abc, http://www.abc.es/ciencia/20130321/abci-imagen-detallada-restosbang-201303211258.html)

La unión de dos nombres, uno de los cuales realiza función de aposición, es otro de los segmentos que están presentes en el corpus, generalmente sin resalte del determinante, como en (8):

(8) (...). La pena específica a reclamar dependerá de si el yerno del Rey abona antes, junto a su exsocio Diego Torres, los cerca de seis millones de euros de los que se apoderaron de las Administraciones públicas.

(...) 
En cuanto a Diego Torres, la pena que la acusación incluirá en su escrito de calificación provisional, que presentará en unos meses, oscilaría entre los diez y los 15 años, puesto que en su caso le será atribuido un solo delito fiscal. En relación con Urdangarin, el Ministerio Público apunta a que el duque defraudó al IRPF más de 120.000 euros tanto en 2007 como en 2008 a través de la empresa Aizoon, cuya titularidad comparte al 50\% con la infanta Cristina.

(Público, http://www.publico.es/politica/501030/ la-fiscalia-pedira-de-10-a-19-anos-de-carcel-para-inaki-urdangarin)

Se han documentado también abundantes casos de nombre + adjetivo y de nombre + SP, resaltados igualmente sin determinante. Así se observa en (9) en los segmentos delito fiscal, blanqueo de capitales, gastos fraudulentos y Estado de derecho:

(9) El juez José Castro ha imputado este martes a la infanta Cristina por delito fiscal y blanqueo de capitales en el 'caso Noos'. En un extenso auto de 227 folios, el titular del juzgado de instrucción número 3 de Palma concluye que hay indicios delictivos suficientes en el comportamiento de la hija del Rey y le cita a declarar el próximo 8 de marzo, a las 10 horas.

Tres años después de iniciar la investigación del 'caso Noos', una pieza separada de la macrocausa del Palma Arena, y ocho meses después de rastrear la actividad económica de la infanta Cristina, el juez vuelve a encausarla. Según detalla en su auto, existen indicios de que la hija del Rey se prestó a que Aizoon, la sociedad que comparte al 50\% con su marido, Iñaki Urdangarin, "sirviera de andamiaje imprescindible para la comisión de delitos fiscales" y realizó gastos fraudulentos con fondos de la empresa.

(..)

Asimismo, considera que el hecho de citar a Cristina para que explique las supuestas irregularidades no hará "tambalear los pilares del Estado de derecho, más bien todo lo contrario".

(El Periódico, http://www.elperiodico.com/es/noticias/politica/juez-castro-imputa-infantacristina-delito-fiscal-blanqueo-capitales-caso-noos-2988109) ${ }^{6}$

Asimismo, se identifican casos de sintagmas nominales completos resaltados en negrita, con inclusión del determinante, como en (10):

(10) Fue el 23 de enero del pasado año cuando el Parlament dictó una primera declaración soberanista que no contó con el apoyo del PSC y sí recabó el aval de CiU, ERC e ICV. En esta primera declaración, el Parlament defendía que Cataluña es «sujeto jurídico y político soberano». Posteriormente, el 13 de marzo, el Parlament aprobó por una amplia mayoría, más de dos tercios de la Cámara (104 votos), una resolución en la que se instó al Gobierno de la Generalitat a «iniciar un diálogo» con el Ejecutivo central para celebrar una consulta de autodeterminación en Cataluña. Esta iniciativa fue votada a favor por CiU, ERC, ICV-EUiA y PSC.

$(A b c$, http://www.abc.es/espana/20140214/abci-constitucional-catalua-201402140151.html)

6 Para mayor claridad, hemos eliminado del ejemplo la negrita original de los siguientes nombres propios y nombres comunes: José Castro, infanta Cristina, caso Noos, Palma Arena, Aizoon, Iñaki Urdangarín, andamiaje. 
Aproximadamente el 65\% de los segmentos resaltados en negrita del corpus corresponden a elementos nominales y el $50 \%$ de ellos son solo nombres. No se han documentado, en cambio, verbos resaltados en negrita. Sí constan en el corpus segmentos de verbo + argumento, de verbo + CC o sintagmas verbales completos como en (11):

(11) La ley de 1985, que se mantuvo intacta hasta 2010 con dos legislaturas populares en medio, despenalizaba el aborto en tres supuestos y en dos tiempos. Si había violación, era legal hasta las 12 semanas de gestación. Y si había malformación del feto, hasta las 22.

Pero el llamado tercer supuesto tenía que ver con el "grave riesgo" para la salud "física o psíquica" de la mujer. Y no establecía ningún límite en el tiempo.

La ley de 2010 sacó al aborto del Código Penal (excepto en alguna circunstancia) y lo convirtió en un derecho de la mujer. Aquel texto, que desaparece hoy, facilitaba las cosas a la mujer durante las primeras semanas, pero se las complicaba a partir de la semana 22, cuando sólo una circunstancia extrema del feto y no de ella justificaran la interrupción del embarazo.

(El Mundo, http://www.elmundo.es/espana/2013/12/20/52b34702268e3e70218b4573.html)

El corpus contiene también ejemplos de realce de cláusulas, como en (12), donde se destaca en negrita incluso la conjunción, que, en otros casos, no se incluye en el segmento marcado:

(12) El magistrado atribuye además a la Infanta Cristina la contratación "en negro" de su servicio doméstico y destaca que ella misma participaba en la selección del personal: "Si hemos de creer a los testigos, empleados del hogar familiar del matrimonio, y no hay de momento razón alguna para no hacerlo, en su contratación intervino personalmente Doña Cristina de Borbón y Grecia anunciando a los aspirantes, cuya situación irregular en España conocía aquélla, que de ser contratados se les abonarían sus salarios en 'negro' accediendo a documentar las relaciones sólo cuando, tras su verbal y efectiva contratación, los empleados se lo pidieron para obtener el permiso de residencia pero haciendo figurar entonces como empresa contratante a Aizoon S. L. cuando los empleados nunca prestaron sus servicios para tal entidad".

(El Mundo, http://www.elmundo.es/espana/2014/01/07/52cbcbe9268e3e91448b456f.htmll)

No son infrecuentes los casos en que el periodista opta por realzar oraciones completas, como puede advertirse en (13):

(13) No obstante, los argumentos de Asúa han generado un profundo malestar entre la mayoría del TC, cuyo presidente, Francisco Pérez de los Cobos, aspiraba a ofrecer una imagen de unidad jurídica frente al desafío secesionista planteado por la Generalitat catalana.

De momento, el acuerdo del Parlament se encuentra suspendido desde el 8 de marzo de 2013, día en el que el Gobierno impugnó el acuerdo, una suspensión ratificada «a posteriori» tras el recurso del Parlament.

(Abc, http://www.abc.es/espana/20140214/abci-constitucional-catalua-201402140151.html)

Tal y como ponen de manifiesto los ejemplos incluidos en las líneas precedentes, en muchos casos, los periodistas resaltan, mediante el recurso tipográfico del que nos ocupamos, unidades gramaticales completas. Sin embargo, no son infrecuentes los segmentos inconsistentes desde el punto de vista de la segmentación. En algunos casos, la inconsistencia parece 
deberse a falta de atención, tal vez a causa del apremio con que llevan a cabo su tarea los profesionales del periodismo, como en los ejemplos (14) y (15):

(14) El explorador lunar «quedó desactivado cuando mostraba un estatus anormal», explicó Pei. (Abc, http://www.abc.es/ciencia/20140213/abci-yutu-robot-despierta-201402130914.html)

(15) Holanda y Suecia tienen las legislaciones más permisivas de la Unión Europea, con aborto libre durante las primeras 24 y 18 semanas de gestación, respectivamente. Fuera de Europa, naciones como Canadá, EEUU, Australia, Rusia o China disponen igualmente de legislaciones permisivas, mientras que en América Latina y África la norma general son leyes restrictivas que penalizan el aborto.

(Público, http://www.publico.es/actualidad/491870/

la-reforma-de-la-ley-del-aborto-mas-cerca-de-latinoamerica-que-de-la-ue)

Se trata de pequeñas inconsistencias formales que apenas afectan a la lectura de las piezas informativas. Pero, en algunos casos, como los que pueden observarse en (16), constituyen imprecisiones que podrían evitarse acordando y respetando un criterio claro; en este caso, precisamente, la decisión acerca de si se realza la conjunción entre dos nombres coordinados marcados en negrita. En (16), el periodista incluye la conjunción en el primer caso y no en el siguiente:

(16) (...) los dos instructores del caso Palau, Juli Solaz y Josep Maria Pijuan, jueces de instrucción como Josep Maria Miquel Porres y Josep Niubó, y el magistrado de la Audiencia de Barcelona Santiago Vidal.

(Abc, http://www.abc.es/catalunya/politica/20140213/abci-jueces-catalanes-firmanmanifiesto-201402131849.html)

Del mismo modo, en el ejemplo (17), se trata de ser consecuente en el realce de la preposición:

(17) Los magistrados también apelan a «la voluntad del pueblo» como «base de la autoridad del poder público» recogida en Declaración Universal de Derechos Humanos y «al derecho de los pueblos a su libre determinación», incluido en el Pacto Internacional de Derechos Económicos, Sociales y Culturales.

(Abc, http://www.abc.es/catalunya/politica/20140213/abci-jueces-catalanesfirman-manifiesto-201402131849.html

Hay en el corpus otros casos de marcación inconsistente desde el punto de vista formal. Un ejemplo puede verse en (5). En el primer párrafo del fragmento, el periodista marca tres segmentos de la misma frase: "el Gobierno ha aprobado la ley del aborto más restrictiva de la democracia." Los tres segmentos señalan los elementos gramaticales correspondientes a cuatro funciones gramaticales distintas, pues el segundo incluye el elemento léxico de una forma verbal compuesta con su argumento, que aparece resaltado con el determinante incluido. Los determinantes de los nombres realzados en el primer y el tercer segmento no están en negrita, así como tampoco el polo gramatical de la forma verbal compuesta. Por otro lado, desde el punto de vista del contenido, no se puede afirmar que el concepto "democracia" resulte más relevante para la comprensión de la frase que el expresado mediante el 
modificador "más restrictiva". En definitiva, se podría suponer que el redactor de la noticia evita realzar la frase completa, tal vez siguiendo una norma de estilo del medio; con todo, el corpus que hemos estudiado incluye oraciones marcadas en negrita extraídas de piezas informativas de $A b c$, como el ejemplo reproducido en (13), de modo que es lícito plantearse si, en el caso que analizamos, no hubiera sido recomendable realzar toda la frase.

No son escasos, pues, en el corpus, los ejemplos de marcación formalmente inconsistente de los segmentos realzados. Incluimos a continuación un fragmento que contiene dos ejemplos más:

(18) La ignorancia era aún más profunda en el proceder de Cristina, puesto que el puro desconocimiento ha sido su respuesta ante el interés de Castro por conocer a quién pertenecía la filiación laboral de los empleados domésticos de la residencia de los Urdangarin-Borbón en Barcelona. Unos empleados extranjeros que, ilegales y pagados en negro según el juez instructor, había seleccionado ella misma. Cristina Federica de Borbón y Grecia no sabía que esos empleados eran de Aizoon S.L. Una vez más, unos gastos privados cargados como gastos de la empresa común. Un hecho que Castro considera probado, y que conllevaría delito fiscal en el caso de superar los 120.000 euros en el monto de la defraudación a la Hacienda pública.

La ignorancia también ha servido como argumento para despachar el asunto del origen del dinero de Aizoon S.L. La infanta Cristina jamás supo, así lo ha declarado, que ese dinero provenía de Nóos, punto central sobre el que Castro basa sus indicios sobre el delito de blanqueo de dinero que pesa sobre la imputada. Todo lo que Cristina de Borbón sabía cuando firmó lo que firmó en Aizoon S.L. es que confiaba en su marido, la "teoría del amor" como la ha bautizado la abogada Negrete.

(Público, http://www.publico.es/politica/500860/la-infanta-declaraal-juez-que-no-sabia-ni-lo-que-firmaba)

Para concluir este apartado de nuestro trabajo, cabe ilustrar, a través de un mismo fragmento que comparten dos noticias del corpus, que las inconsistencias en el uso de la negrita se producen en un mismo medio:

(19a) El juez José Castro ha imputado a la Infanta Cristina por un delito de blanqueo de capitales y otro fiscal presuntamente cometidos por la hija del Rey en su condición de copropietaria de Aizoon, empresa familiar a la que se desviaron más de un millón de euros públicos desde el Instituto Nóos.

(El Mundo, http://www.elmundo.es/espana/2014/01/07/52cbcbe9268e3e91448b456f.html)

(19b) El juez José Castro ha imputado a la Infanta Cristina por un delito de blanqueo de capitales y otro fiscal presuntamente cometidos por la hija del Rey en su condición de copropietaria de Aizoon, empresa familiar a la que se desviaron más de un millón de euros públicos desde el Instituto Nóos.

(El Mundo, http://www.elmundo.es/espana/2014/01/07/52cba147268e3ea3448b456a. html?cid=MNOT23801\&s_kw=la_infanta_cristina_imputada_ por_blanqueo_y_delito_fiscal)

En suma, el análisis de los elementos resaltados en negrita en las piezas informativas de los distintos periódicos revela un uso asistemático de este recurso desde el punto de vista formal, incluso por parte de los profesionales de un mismo medio informativo. Así, pese a 
que, como se subrayará en este trabajo, la negrita cumple una función relevante en la lectura e interpretación de los textos digitales, el resalte aleatorio de los segmentos lingüísticos refleja la escasa atención que los trabajos normativos han prestado a los aspectos tipográficos de la lengua escrita, en general, y de los textos en soporte digital, en particular.

\subsection{Descripción funcional}

La negrita, como apuntábamos en el apartado 3, se ha descrito generalmente como un recurso tipográfico orientado, fundamentalmente, a la focalización de la información. El aumento del grosor de la letra aumenta consecuentemente el grado de prominencia -esto es, de saliencia- del elemento resaltado (Van Leeuwen, 2006: 148), de modo que se llama la atención del lector sobre dicho elemento, que cobra mayor relevancia en el contexto y genera una expectativa acerca de su importancia potencial. En este sentido, la negrita, en tanto que rasgo tipográfico, resalta elementos informativos del texto (función de resalte informativo), centrando la atención del lector sobre ellos. Esta función de resalte (informativo) representa una función genérica o macrofunción del uso de la negrita que suele materializarse contextualmente en usos más concretos que encajan dentro de alguna de las tres metafunciones comunicativas de Halliday (1978) aludidas anteriormente: ideacional, interpersonal y textual. En lo que sigue, presentamos una descripción de los usos de la negrita que hemos encontrado en el corpus analizado, asociando cada uno de ellos con su correspondiente metafunción comunicativa.

\subsubsection{Negrita y cohesión: la metafunción textual}

Como apuntábamos más arriba (ver $\S 4$ ), una de las metafunciones comunicativas más destacadas del rasgo tipográfico "grosor del tipo de letra", esto es, de la negrita, es la metafunción textual. En nuestro corpus, esta metafunción se concreta en las funciones siguientes ${ }^{7}$ :

- Localizar palabras y conceptos relevantes del texto

- Resaltar contenidos del texto

- Crear itinerarios de lectura rápida

Todas estas funciones sirven para cohesionar y estructurar el discurso, dotando de relevancia visual (saliencia) ciertos elementos sobre los que se requiere la atención del receptor/ lector; constituyen, pues, focos de atención. La focalización de estos elementos ayuda, por un lado, al lector a localizar palabras y contenidos clave en el texto, resaltándolos como elementos informativos o sugiriendo itinerarios de lectura rápida; y, por otro, al redactor a cohesionar y estructurar el contenido.

La tabla 3 muestra el reparto de las funciones anteriores en función del periódico y de la sección en que aparecen.

7 En este trabajo, no consideramos el uso de la negrita para optimizar la búsqueda automática de contenidos, ya que esta función excede el interés de este estudio. 


\begin{tabular}{|c|c|c|c|c|}
\hline & & $\begin{array}{c}\text { Localizar } \\
\text { palabras clave }\end{array}$ & $\begin{array}{c}\text { Resaltar } \\
\text { contenidos }\end{array}$ & $\begin{array}{c}\text { Itinerario de } \\
\text { lectura }\end{array}$ \\
\hline \multirow[b]{2}{*}{ El País } & $\mathrm{J}$ & 0 & 0 & 0 \\
\hline & $\mathrm{C}$ & 0 & 0 & 0 \\
\hline \multirow{2}{*}{ La Vanguardia } & $\mathrm{J}$ & 5 & 0 & 0 \\
\hline & $\mathrm{C}$ & 3 & 1 & 0 \\
\hline \multirow{2}{*}{ Público } & $\mathrm{J}$ & 2 & 3 & 1 \\
\hline & $\mathrm{C}$ & 0 & 1 & 2 \\
\hline \multirow{2}{*}{ El Periódico } & $\mathrm{J}$ & 4 & 0 & 0 \\
\hline & $\mathrm{C}$ & 3 & 0 & 0 \\
\hline \multirow{2}{*}{$A B C$} & $\mathrm{~J}$ & 1 & 3 & 2 \\
\hline & $\mathrm{C}$ & 0 & 3 & 1 \\
\hline \multirow[b]{2}{*}{ El Mundo } & $\mathrm{J}$ & 3 & 5 & 1 \\
\hline & $\mathrm{C}$ & 0 & 2 & 1 \\
\hline \multicolumn{2}{|c|}{$\begin{array}{c}\mathrm{N}^{\circ} \text { total por } \\
\text { función }\end{array}$} & 21 & 18 & 8 \\
\hline
\end{tabular}

Tabla 3. Número de piezas informativas según medio y función predominante.

\subsubsection{Localizar palabras y conceptos relevantes}

El uso más frecuente de la negrita en las piezas informativas que se han analizado (ver tabla 3) es el de llamar la atención del lector sobre determinados nombres y sintagmas nominales que hacen referencia a personajes e instituciones (nombres propios) o conceptos clave del hecho noticiado.

Con esta función de localización de palabras clave, se han documentado ejemplos en todas las piezas informativas de los periódicos analizados, a excepción de El País, que no utiliza la negrita en el cuerpo del texto (ver §6.1). Llama la atención que es mayor el empleo de la negrita con esta función en las noticias y crónicas de contenido jurídico que en las de tema científico: 15 piezas informativas en el primer caso, frente a 6 en el segundo (ver tabla 3). Como señalábamos en el apartado 4, es posible que la mayor incidencia del uso de la negrita con esta función en el subcorpus legal se deba a una mayor necesidad informativa de señalar determinados segmentos de información con fuerza argumentativa o carga significativa clave, generalmente personajes involucrados en los hechos noticiados y determinados conceptos relevantes para comprender el alcance o la gravedad del asunto narrado (a menudo términos especializados de diversas disciplinas científicas, médicas o judiciales).

Por lo general, como muestran los ejemplos (20) y (21), se trata de fragmentos de información inconexos entre sí que no conforman una estructura coherente per se (no permiten una lectura rápida de la noticia que la "resuma"), sino que han de contextualizarse dentro del texto; esto es, ponerse en relación con la información circundante para aprehender su alcance dentro de la noticia o crónica.

(20) Barcelona. (Agencias). El fiscal Anticorrupción Pedro Horrach puede pedir hasta 17 años de prisión para el duque de Palma, Iñaki Urdangarin. En cambio, de no encausar a la 
Infanta, confirmando así una postura alejada de la mantenida en su imputación por el juez José Castro, Doña Cristina debería pagar un monto de 600.000 euros por responsabilidad civil.

Cuando se encara el tramo final del caso Nóos, y considerando los diferentes delitos de malversación, falsedad y otros fiscalesque se juzgan en los juzgados de Palma de Mallorca, Horrach podría reclamar al Duque de Palma hasta 17 años de cárcel y considerar hasta 15 para su exsocio Diego Torres.

(La Vanguardia, http://www.lavanguardia.com/politica/20140210/54400110142/ fiscalia-carcel-urdangarin.html)

(21) Gran paso para la fusión nuclear. Investigadores estadounidenses han logrado por primera vez que un experimento de fusión nuclear produjera más energía que la necesaria para ponerlo en marcha, un paso prometedor hacia el desarrollo de una nueva fuente energética limpia, ya que no genera residuos, e ilimitada, pues su combustible es el hidrógeno, uno de los componentes del agua.

El experimento, extraordinariamente fugaz, se realizó el pasado noviembre en la National Ignition Faciliity (NIF), una infraestructura de investigación del Gobierno de Estados Unidos con grandes aplicaciones en el sector militar, pero no se ha dado a conocer hasta comprobar la exactitud de los datos. Los detalles de la investigación se han publicado en la revista 'Nature'.

(El Periódico, http://www.elperiodico.com/es/noticias/ciencia/gran-paso-para-fusionnuclear-rentable-3096656)

\subsubsection{Resaltar contenidos}

Otra de las subfunciones metatextuales de la negrita que presenta un índice de uso elevado en el corpus analizado es la de resaltar segmentos de información que se consideran relevantes para la comprensión de la noticia. Como ocurría con la función descrita en el apartado anterior, el resalte de contenidos tiene mayor presencia en las noticias y crónicas de contenido legal (11 piezas informativas) que en las de tema científico (7 piezas informativas). Por su parte, si se compara el uso de la negrita como recurso para localizar palabras y conceptos con el uso que estamos describiendo ahora, la diferencia en cada subcorpus no resulta muy significativa. Hay un ligero descenso en el corpus legal: $15 / 11$, y un pequeño aumento en el científico: 6 / 7 (ver tabla 3).

Con esta función, los segmentos marcados en negrita exceden el límite gramatical del nombre sin determinación o el SN simple $(\mathrm{N}+$ adj), como muestra la siguiente pieza informativa (22a), que copiamos íntegra: estos fragmentos no aluden a personajes o conceptos clave de la noticia, sino a información más compleja.

(22a) Las 6 horas y media que la infanta Cristina ha estado [declarando como imputada ante el juez Castro] ${ }_{1}$ han servido para dos cosas. (1er párrafo)

Sino por el [reguero de interrogantes que no han sido despejados] ${ }_{2}$ por su declaración; ( $2^{\circ}$ párrafo)

(...) han consistido en mostrar un gran número de pruebas de gasto, facturas y comprobantes de compras que José Castro ha ido acumulando en la instrucción del sumario (...). (3er párrafo) 
Las respuestas que ha conseguido hilvanar la hija del rey (cuya efigie presidía la sala de juicios) [han llegado a merecer el calificativo de "vergüenza ajena" $]_{3}$ oído en las voces de los abogados Manuel Delgado y Virginia Negrete, representantes de las acusaciones populares del Frente Cívico Julio Anguita y de Manos Limpias, respectivamente. ( $4^{\circ}$ párrafo) $\mathrm{La}$ [ignorancia era aún más profunda en el proceder de Cristina] ${ }_{4}$, puesto que el puro desconocimiento ha sido su respuesta ante el interés de Castro por conocer a quién pertenecía la filiación laboral de los empleados domésticos de la residencia de los UrdangarinBorbón en Barcelona. (...). ( $5^{\circ}$ párrafo)

(...)Todo lo que Cristina de Borbón sabía cuando firmó lo que firmó en Aizoon S.L. es que [confiaba en su marido, la "teoría del amor" $]_{5}$ como la ha bautizado la abogada Negrete. (...) ( $6^{\circ}$ párrafo)

(...)"Ha colaborado con la justicia sin privilegios" se vanagloriaba el abogado catalán, minutos después que el vehículo que transportaba a la hija del rey hubiera abandonado el patio del juzgado, como medida de especial y excepcional seguridad, inédita para el resto de imputados de la causa, incluido su consorte. (...) ( $7^{\circ}$ párrafo)

El juez Castro, que ha evitado el tratamiento de alteza para la imputada (se ha dirigido a ella como señora todo el interrogatorio), [ha empleado las 5 horas de la sesión matinal de la citación $]_{6}$ para plantear más de 400 cuestiones diferentes a Cristina de Borbón. (...) ( $8^{\circ}$ párrafo)

El instructor de la causa, que por la mañana ha escuchado [vítores y gritos en su favor de los ciudadanos $]_{7}$ concentrados ante el juzgado, (...). ( $9^{\circ}$ párrafo)

A diferencia de los casos anteriores, en que la negrita marca palabras o combinaciones sintagmáticas simples que no guardan entre sí una relación cohesiva, los fragmentos de mayor contenido señalados en negrita sí presentan un grado mayor de cohesión y permiten un escaneo rápido del contenido, tal como puede comprobarse en (22b), donde se han aislado los segmentos informativos destacados en negrita:

(22b) declarando como imputada ante el juez Castro reguero de interrogantes que no han sido despejados pruebas de gasto, facturas y comprobantes de compras han llegado a merecer el calificativo de "vergüenza ajena ignorancia era aún más profunda en el proceder de Cristina confiaba en su marido, la "teoría del amor medida de especial y excepcional seguridad ha empleado las 5 horas de la sesión matinal de la citación vítores y gritos en su favor de los ciudadanos

Casos como el anterior denotan un cierto esfuerzo del periodista por sintetizar estratégicamente fragmentos relevantes de la información global de la noticia o crónica. No obstante, la inconsistencia formal de los segmentos marcados (no se marcan elementos referenciales necesarios para comprender el segmento marcado de un solo vistazo) conlleva también inconsistencias semánticas, lo cual provoca que el escaneo resulte incompleto e infructuoso.

Aunque los ejemplos anteriores responden a casos prototípicos del uso de la negrita para localizar palabras y conceptos relevantes $(20$ y 21$)$ y resaltar contenidos del texto (22a y $22 \mathrm{~b}$ ), no es infrecuente que ambos usos coaparezcan en una misma pieza informativa: 
(23) En el vídeo, grabado con la cámara ladeada y la imagen vibrando, se aprecia a la infanta Cristina por detrás, respondiendo a las preguntas del juez, mientras que se escuchan silbidos y protestas en la calle.

El juez Castro pregunta sobre las actividades del Instituto Nóos mientras muestra en una pantalla documentos y correos electrónicos relacionados con esas actividades, (...).

(...). Para ello, estableció la obligación de que todas las personas que accedieron a la sala, unas cuarenta entre abogados defensores, fiscales, representantes de la acusación y funcionarios, depositaran bajo custodia policial antes de entrar sus teléfonos móviles, tabletas, ordenadores portátiles o cualquier otro dispositivo que pudiera grabar imágenes o sonido.

(Público, http://www.publico.es/500997/no-lo-se-y-no-me-acuerdolas-respuestas-tipo-de-la-infanta)

\subsubsection{Crear itinerarios de lectura rápida}

En algunos casos, además de una localización rápida de información clave, el resalte de fragmentos relevantes del texto permite también establecer un itinerario de lectura rápida que funciona a modo de resumen del contenido principal de la noticia. Tal como muestran los ejemplos (24) y (25), los segmentos resaltados en negrita guardan entre sí una relación de coherencia y conforman una microtexto que recoge la información esencial de la pieza informativa. De este modo, la negrita establece un primer plano de lectura que permite al lector llevar a cabo un escaneo rápido sobre pantalla y decidir si le interesa profundizar en la noticia, accediendo a un plano de lectura más profundo.

En el ejemplo (24), la pieza informativa original, que trata sobre la implicación del ministro Gallardón en el extravío de la solicitud de indulto del juez Garzón, consta de 468 palabras. Sin embargo, la selección estratégica de determinados fragmentos informativos más el titular, que supone información determinante para la comprensión de la noticia abreviada, permite condensar la información clave en 110 palabras:

(24) Gallardón no asume ninguna culpa por el extravío de la solicitud de indulto a Baltasar Garzón

su actuación una vez que se conoció la pérdida del expediente ha sido "ágil y legal"

no fue hasta el pasado verano cuando el Gobierno se enteró por la prensa del extravío de la petición

El Alto Tribunal dijo que no había recibido la solicitud de indulto para Garzón, y eso que sí le llegaron otras seis peticiones

Justicia "asumió con normalidad el retraso en la recepción de los informes

"hay 35 peticiones de informes pendientes de respuesta cuyo oficio de remisión a los tribunales se envió en el mes de junio de 2012

(Público, http://www.publico.es/politica/500144/gallardon-no-asume-ninguna-culpapor-el-extravio-de-la-solicitud-de-indulto-a-baltasar-garzon) 
Lo mismo puede observarse en el ejemplo (25). Se trata de una noticia sobre el descubrimiento de un agujero negro y su estrella, cuyo contenido se extiende a lo largo de 37 líneas y 399 palabras. Igual que en el caso anterior, el texto original se resume mediante cuatro fragmentos marcados en negrita, dos al principio y dos al final de la noticia, que constituyen un minitexto de 42 palabras:

(25) una estrella y un agujero negro orbitan entre sí a un ritmo de locos, una vez cada 2,4 horas, a una velocidad vertiginosa de dos millones de kilómetros por hora casi 20 veces más rápido que la Tierra gira alrededor del Sol.

( $A B C$, http://www.abc.es/ciencia/20130320/abci-descubren-desbocados-agujero-negro-201303201116.html)

Un caso tal vez extremo, pero excelente desde el punto de vista estratégico, es el que muestra el ejemplo (26), en que la selección de un breve fragmento de información (7 palabras) condensa el contenido informativo clave de la noticia (308 palabras) y responde a la pregunta implícita en el titular: «La NASA pone fin al misterio del "donut" aparecido en Marte»:

(26) un pedazo desprendido de una roca mayor

(Público, http://www.publico.es/502148/la-nasa-pone-fin-al-misteriodel-donut-aparecido-en-marte)

Tal como muestran los ejemplos anteriores, se observa que el uso de la negrita puede orientarse estratégicamente hacia funciones textuales que permitan un acceso fácil y rápido a la información; asimismo, este uso denota también un mayor grado de conciencia por parte del periodista respecto de su tarea de planificar y diseñar itinerarios de lectura.

\subsubsection{Intensificación del contenido: la metafunción interpersonal}

Otra de las funciones que puede desempeñar la negrita en las piezas informativas analizadas es la metafunción interpersonal. Con este uso de la negrita, se intensifican contenidos para guiar al lector hacia determinadas actitudes respecto del hecho noticiado, tales como (des)afección, empatía, etc.

En todas las piezas informativas analizadas, el resalte de la información cumple fundamentalmente una función textual relacionada con la localización de palabras y contenidos clave que ayudan al lector a retener información relevante para comprender el alcance de la noticia. No obstante, en algunos casos, este resalte de información va más allá de la mera función textual.

Así, por ejemplo, en la siguiente pieza informativa la negrita llama la atención no solo sobre determinadas palabras clave del texto, sino también sobre aspectos valorativos del segmento en cuestión que se interpretan contextualmente. De este modo, se lleva a cabo una intensificación del valor conceptual del término o del fragmento resaltado en negrita, cuyo valor semántico se incrementa con valores connotativos que sugieren en el lector un cierto juicio de valor sobre el hecho noticiado. Así, en el ejemplo (27), los segmentos destacados en negrita crean una imagen negativa de la protagonista principal de la noticia, la infanta 
Cristina, y sugieren en el lector una lectura de condena sobre la actuación de los imputados y de aplauso hacia la actuación del juez instructor:

\section{(27) titular La infanta declara al juez que no sabía ni lo que firmaba}

(1er párrafo) Las 6 horas y media que la ha estado declarando como imputada ante el juez Castro han servido para dos cosas.

Si es cierto que el desconocimiento de la ley no es un eximente para su cumplimiento, y que su aplicación a la luz de los hechos y sus consecuencias iguala a todos los ciudadanos, entonces se puede colegir que la infanta ha salido de los juzgados de Vía Alemania en Palma de Mallorca peor de lo que

$\left(2^{\circ}\right.$ párrafo) ha entrado. Y no por haber pisado la manida rampa, que ha atravesado en la butaca trasera de un coche oficial. Sino por el reguero de interrogantes que no han sido despejados por su declaración;

Gran parte de la batería de preguntas que el juez instructor ha ido planteando a Cristina, en un interrogatorio que ha sido alabado sin ambages por la acusación popular y tildado de muy correcto por parte de la defensa, han consistido en mostrar un gran número de pruebas de gasto, facturas y comprobantes de

(3er párrafo) compras que José Castro ha ido acumulando en la instrucción del sumario gracias a los informes de la Agencia Tributaria, y de cuya existencia ya se había dado cuenta en el escrito de imputación de la infanta del pasado 8 de enero.

Las respuestas que ha conseguido hilvanar la hija del rey (cuya efigie presidía la sala de juicios) han llegado a merecer el calificativo de "vergüenza ajena"

( $4^{\circ}$ párrafo) oído en las voces de los abogados Manuel Delgado y Virginia Negrete, (...).

La ignorancia era aún más profunda en el proceder de Cristina, puesto que el puro desconocimiento ha sido su respuesta ante el interés de Castro por

( $5^{\circ}$ párrafo) conocer a quién pertenecía la filiación laboral de los empleados domésticos de la residencia de los Urdangarin-Borbón en Barcelona.

(....).Todo lo que Cristina de Borbón sabía cuando firmó lo que firmó en Aizoon S.L. es que confiaba en su marido, la "teoría del amor"como la ha bautizado

( $6^{\circ}$ párrafo) la abogada Negrete. (...).

(...).”Ha colaborado con la justicia sin privilegios" se vanagloriaba el abogado catalán, minutos después que el vehículo que transportaba a la hija

( $7^{\circ}$ párrafo) del rey hubiera abandonado el patio del juzgado, como medida de especial y excepcional seguridad, inédita para el resto de imputados de la causa, incluido su consorte. (...). ( $7^{\circ}$ párrafo)

( $8^{\circ}$ párrafo) El juez Castro, que ha evitado el tratamiento de alteza para la imputada (se ha dirigido a ella como señora durante todo el interrogatorio), ha empleado las 5 horas de la sesión matinal de la citación para plantear más de 400 cuestiones diferentes a Cristina de Borbón. (...).

( $9^{\circ}$ párrafo, El instructor de la causa, que por la mañana ha escuchado vítores y gritos en último) su favor de los ciudadanos concentrados ante el juzgado, y que a su salida ha sido aplaudido por algunos curiosos que se apostaban al borde de la rampa, (...).

(Público, http://www.publico.es/politica/500860/la-infanta-declara-al-juez-que-no-sabia-ni-loque-firmaba) 
Este valor añadido de la negrita puede captarse mejor comparando el tratamiento que confieren otros periódicos a la misma noticia. En todos los periódicos analizados (a excepción de El País, que, reiteramos, no utiliza la negrita en el cuerpo de la noticia), se marcan los nombres de personajes relevantes de la noticia. Sin embargo, no todos los medios ponen el foco de atención sobre las causas de la imputación, esto es, sobre los delitos de los que se acusa a los imputados de la noticia. Un ejemplo de ello puede observarse en la siguiente pieza informativa del periódico $A b c$, del mismo día que la noticia del ejemplo (27), que informa sobre el mismo suceso (la comparecencia de la infanta Cristina ante el juez Castro):

\section{(28) Iñaki Urdangarín}

Pedro Horrach

ha abandonado los juzgados de Palma a las 18.12 horas

se despidió con un saludo general a los periodistas

utilizó la tarjeta de Aizoon para gastos personales

Doña Cristina no ha incurrido en ninguna contradicción y se ha mostrado muy tranquila en todo momento

Desconocer las actividades que allí se llevaban a cabo

La infanta ha señalado que "tenía mucha confianza" en su marido

El magistrado ha preguntado factura por factura por los gastos de Aizoon

Jesús Silva

Manuel Delgado

Virginia López Negrete

saludó tres veces con un "buenos días".

Acompañaba a la infanta su abogado, Miquel Roca.

Jesús Silva

ni los gritos ni los pitidos de los manifestantes

(Abc, http://www.abc.es/espana/20140208/abci-infanta-llegada-201402080953.html)

La diferencia en el uso de la negrita no parece responder solo a una distinta orientación del foco de atención, sino que podría deberse también a la intención del periodista (o de la línea editorial del periódico) de intensificar determinadas relaciones causales entre el delito y la imputación, así como de crear una determinada imagen del protagonista de la noticia. Dado que los términos resaltados en negrita son datos marcados que presumiblemente retendrá el lector en la memoria, la marcación parece orientarse a crear en el lector una predisposición (des)favorable hacia dicha relación causal y hacia el personaje noticiado.

Así, en (27), Público incide en las acciones presuntamente delictivas por las que debe responder la infanta ante el juez instructor y en en la actuación de la infanta durante la comparecencia. De esta forma, aunque la información resaltada es información factual clave para entender la noticia, orienta al lector hacia la construcción de una determinada imagen desfavorable del protagonista de los hechos:

(27 bis) La infanta declara al juez que no sabía ni lo que firmaba declarando como imputada ante el juez Castro el reguero de interrogantes que no han sido despejados por su declaración Las respuestas que ha conseguido hilvanar la hija del rey (cuya efigie presidía la sala de juicios) han llegado a merecer el calificativo de "vergüenza ajena" La ignorancia era aún más profunda en el proceder de Cristina confiaba en su marido, la "teoría del amor" 
En cambio, los fragmentos destacados por el diario $A b c$ crean una imagen más "amable", colaborativa, de la infanta:

(28bis) se despidió con un saludo general a los periodistas

Doña Cristina no ha incurrido en ninguna contradicción y se ha mostrado muy tranquila en todo momento

Desconocer las actividades que allí se llevaban a cabo

La infanta ha señalado que "tenía mucha confianza" en su marido

El magistrado ha preguntado factura por factura por los gastos de Aizoon saludó tres veces con un "buenos días".

Una lectura comparada de las negritas de las dos piezas informativas ilustra la diferente orientación interpretativa del mismo hecho noticiable que se propone al lector. Compárense, a tal efecto, el contraste entre los siguientes destacados en ambos periódicos:

\section{Público}

$A b c$

Las respuestas que ha conseguido hilvanar la hija del rey (cuya efigie presidía la sala de juicios) han llegado a merecer el calificativo de "vergüenza ajena"

La ignorancia era aún más profunda en el proceder de Cristina
Doña Cristina no ha incurrido en ninguna contradicción y se ha mostrado muy tranquila en todo momento

La hija del rey ha dicho desconocer las actividades que allí se llevaban a cabo

La infanta ha señalado que "tenía mucha confianza" en su marido

\subsubsection{Negrita, connotación y metáfora: la metafunción ideacional}

Según Kress y Van Leeuwen (2002) y Van Leeuwen (2005a; 2005 b), la connotación y la metáfora son los dos principios semióticos que explican cómo aportan los rasgos tipográficos su potencial de significado. Insistimos en que, a través de la connotación, se construye significado potencial por la traslación discursiva de asociaciones desde las ideas y los valores asociados a la letra en el contexto de origen hacia el contexto de destino. Por su parte, la metáfora tipográfica (Van Leeuwen 2005b: 29-36; Van Leeuwen 2006:146-147) se basa en el principio de similitud. Así, el fragmento destacado en negrita puede motivar en su interpretación, mediante una traslación metafórica o un reflejo icónico (Peirce, apud Norgaard 2009: 147-154), conceptos asociados como fuerza, solidez o asertividad. En efecto, los objetos cotidianos de un grosor o de una anchura manifiesta suelen ser sólidos, fuertes, difíciles de romper; igualmente, el "grosor", prosódico o gráfico, de un enunciado le confiere fuerza, solidez argumentativa y manifiesta un mayor compromiso del emisor, cargándose, de este modo, con un valor añadido de solidez o asertividad.

La metafunción ideacional de la negrita aparece principalmente en los titulares, ladillos y destacados de las piezas informativas, que suelen presentar un cuerpo, grosor y tipo de letra distintos del cuerpo del texto. Esta combinación de rasgos tipográficos confieren al fragmento informativo mayor relevancia contextual: llama la atención del lector y crea una 
expectativa sobre su potencial significatividad. Pero, al mismo tiempo, como muestra la figura 3, transmiten también valores ideacionales connotativos relacionados con la solidez de esa información y, por tanto, con un mayor compromiso del emisor respecto de esta: solidez informativa, fuerza argumentativa, aserción.

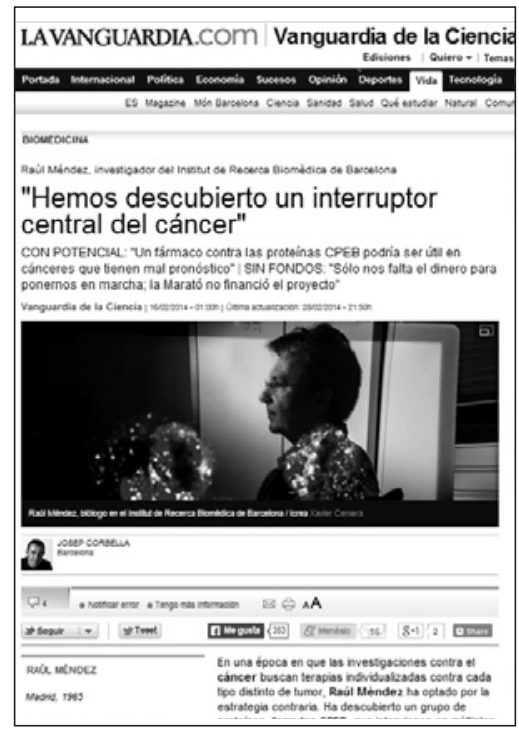

Figura 3. Combinación de rasgos tipográficos con función ideacional en una pieza informativa ${ }^{8}$

Con todo, la función ideacional también puede interpretarse en los casos comentados anteriormente, en que la negrita destaca palabras y contenidos relevantes de la información o establece itinerarios de lectura rápida. En todos ellos, en los que el grosor de la letra dota al elemento destacado de prominencia visual y genera una interpretación por defecto de relevancia informativa, puede interpretarse también un valor metafórico de solidez transmitido por la relación icónica entre el grosor de la letra y el grosor de una estructura física. Este valor conceptual de solidez se reinterpreta discursivamente como fuerza argumentativa (la solidez física del fragmento destacado en negrita implica en el discurso mayor relevancia informativa en relación con el resto de elementos no marcados) y, en buena medida, como un determinado grado de compromiso del emisor respecto de la importancia de la información que resalta (si el periodista destaca un elemento del discurso es porque cree que merece la pena llamar mi atención sobre él).

\section{Conclusiones}

Como apuntábamos en el apartado 4, uno de los objetivos de este trabajo consistía en confirmar los usos descritos por los teóricos del periodismo sobre la negrita. En efecto, la macrofunción de resalte de información de la negrita se manifiesta, especialmente, a través de la metafunción textual, orientada a la cohesión y coherencia informativas: señalar pala-

8 Fuente de la captura de pantalla: La Vanguardia.com (http://www.lavanguardia.com/vanguardia-de-la-ciencia/20140216/54401318691/hemos-descubierto-interruptor-central-cancer.html\#ixzz2xiQe8t) 
bras y conceptos clave, resaltar contenidos y crear itinerarios de lectura rápida. Con todo, la metafunción textual coactúa con las otras dos metafunciones, la ideacional y la interpersonal. Así, por el hecho de distinguirse por un mayor grosor de letra, la negrita satisface una función ideacional relacionada con la solidez de la información destacada; también, en algunos casos, además de señalar palabras clave y contenidos relevantes o crear itinerarios de lectura rápida que cobran relieve argumentativo dentro del cuerpo de la noticia, el resalte de información puede, asimismo, connotar el contenido y orientar al lector hacia determinadas actitudes e interpretaciones en clave ideológica respecto del hecho noticiado.

A modo de resumen, la figura 4 sintetiza los valores funcionales que se han comentado en los apartados anteriores.

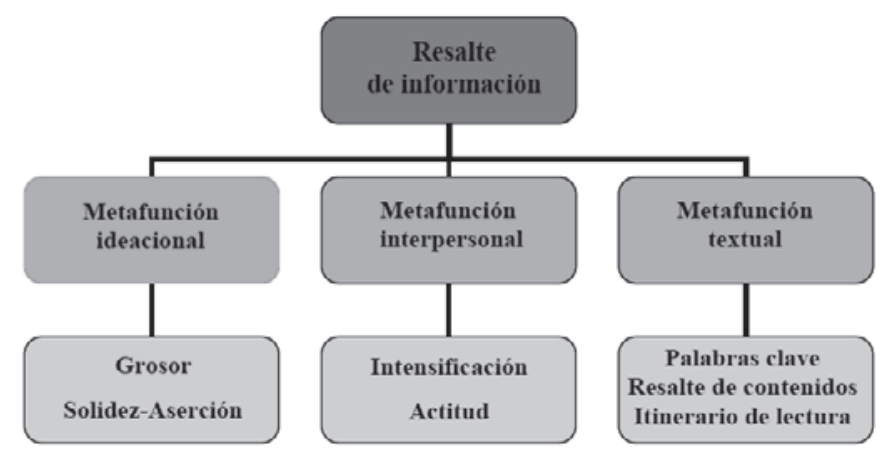

Figura 4: Red funcional de la negrita.

En cuanto a los segmentos textuales que se resaltan en negrita, su tipología y extensión es variable entre periódicos o incluso dentro de un mismo periódico. Esta variabilidad depende, principalmente, del tipo de información que se está destacando. Así, el resalte de palabras y conceptos clave suele corresponderse formalmente con nombres comunes, nombres propios o sintagmas nominales. Por su parte, el resalte de contenidos abarca unidades lingüísticas mayores de límites diversos, dado que la información destacada es más compleja: no se señalan simplemente los protagonistas, los conceptos o las acciones que constituyen las piezas fundamentales de la noticia, sino que se resaltan aspectos de la información que permiten al lector construirse una representación más completa de los hechos noticiados.

Con todo, la marcación de los segmentos presenta, con frecuencia, inconsistencias desde el punto de vista formal. En este sentido, en la mayoría de los casos el segmento destacado en negrita no coincide formalmente con una unidad sintáctica completa. Es frecuente, por ejemplo, que los nombres comunes y los sintagmas nominales en negrita dejen fuera del marcaje el determinante, o que se deje sin marcar la preposición que introduce el complemento nominal.

En este sentido, resulta más llamativo aún que se marquen aleatoriamente segmentos de una unidad sintáctica e informativa mayor, generalmente una oración, fraccionándola de manera que los segmentos destacados no resulten significativos por sí mismos, como muestra este extracto del ejemplo (5):"(...) el Gobierno ha aprobado la ley del aborto más restrictiva de la democracia". En casos como este resultaría más rentable desde el punto de vista informativo destacar en negrita toda la oración (esto es, toda la unidad informativa), sobre todo cuando parte de la información que no queda resaltada es especialmente relevante para entender el 
alcance del hecho noticiado: en el caso particular del extracto del ejemplo (5), que la ley del aborto que aprueba el Gobierno no es una más, sino la más restrictiva de la democracia.

Cabe añadir, por último, que el empleo de la negrita según el subcorpus analizado, científico o jurídico, muestra también diferencias significativas en lo que se refiere al resalte de palabras y conceptos clave, y al resalte de contenidos. Con la primera función, resalte de palabras clave, la negrita se usa en 15 piezas informativas de contenido jurídico, frente a su uso en 6 de contenido científico. Con la segunda función, resalte de contenidos, la negrita tiene mayor presencia en las noticias y crónicas de contenido legal (11 piezas informativas) que en las de tema científico ( 7 piezas informativas). Hemos apuntado a que la mayor incidencia del uso de la negrita con estas funciones en el subcorpus legal se debe, posiblemente, a una mayor necesidad informativa de señalar determinados segmentos clave con fuerza argumentativa o carga significativa que atañen, especialmente, a la identificación de personajes involucrados en los hechos noticiados.

De hecho, solo la función metatextual de la negrita en la creación de itinerarios de lectura rápida presenta la misma proporción de aparición en los subcorpus científico y jurídico. Este uso de la negrita se orienta estratégicamente hacia funciones textuales que permiten un acceso fácil y rápido a la información al establecer un itinerario de lectura rápida que funciona a modo de resumen del contenido principal de la noticia. Revela, asimismo, un mayor grado de conciencia por parte del periodista respecto de su tarea de planificar el texto y diseñar itinerarios de lectura.

En suma, este trabajo propone una reflexión sobre el uso de la negrita para satisfacer metafunciones derivadas de la macrofunción de resalte o focalización. De lo aquí desarrollado se deriva el interés de un futuro análisis sobre la copresencia de la negrita con otros recursos de resalte, en sincretismo multimodal, en la prensa digital, como el cambio del color de la tinta en los hipervínculos o el recurso a letras cursivas.

Asimismo, se ha puesto de relieve la conveniencia de optimizar el uso de la negrita por parte de los profesionales de la prensa digital para lograr una consistencia formal en la delimitación de los elementos destacados que favorezca la legibilidad de la pieza informativa. Del mismo modo, resulta recomendable progresar hacia el desarrollo de itinerarios de lectura abreviada que satisfagan las necesidades de barrido (skimming) y exploración (scanning) de los lectores de prensa en pantalla.

\section{Referencias bibliográficas}

Cassany, D. (2011): En_línia. Llegir i escriure a la xarxa. Barcelona: Graó.

García, M. Á. y Palomeque, C. (2012): "El blog multimodal: la potencialidad comunicativa y de representación de la imagen en interacción con sonidos y texto", Tonos. Revista electrónica de estudios filológicos, 22. [En línea]. Disponible en: https://www.um.es/tonosdigital/ znum22/secciones/estudios-12-el_blog_multimodal_garciaasensio_palomeque.htm

Grice, P. H. (1975): "Logic and Conversation", en Grice, P. (1989): Studies in the Way of Words. Harvard University Press, 22-40.

Halliday, M.A.K. (1978): Language as social semiotic: The social interpretation of language and meaning. London: Edward Arnold.

Jewit, C. (2009): "Different approaches to multimodality", en C. Jewit (ed.) (2009): The Routledge Handbook of Multimodal Analysis. London: Routledge Taylor \& Francis Group.

Kress, G. (2003). Literacy in the new media age. London: Routledge. 
Kress, G. y Van Leeuwen, T. (1992): "Structures of visual representations", Journal of Literay Semantics, 21 (2), 91-117.

Kress, G. y Van Leeuwen, T. (1996): A grammar of visual imagery. London: Routledge.

Kress, G. y Van Leeuwen, T. (2001): Multimodal Discourse. London: Routlege.

Kress, G. y Van Leeuwen, T. (2002): "Colour as a semiotic mode: notes for a grammar of colour", Visual Communication, 1 (3): 343-369.

Kress, G., Leite-García y Van Leeuwen, T. (2000): "Semiótica discursiva”, en T. A. van Dijk (comp.): El discurso como estructura y proceso. Barcelona: Gedisa, 2000, p. 373-416.

Machin, D. (2007): Introduction to Multimodal Analysis. Hodder Arnold: London.

Martínez Albertos, J. L. (1997): Curso de redacción periodística. Madrid: Paraninfo.

Nogaard, N. (2009): “The Semiotics of Typography in Literary Texts. A Multimodal Approach", Orbis Litterarum 64(2), 141-160. [En línea] Disponible en: http://www.sheltonography.com/resources/Articles/SemioticsofTypography.pdf

O’Halloran, K. (2008): "Systemic functional-multimodal discourse analysis (SF-MDA): Constructing ideational meaning using language and visual imagery", Visual Communication, 7(4), 443-474.

Pajares Tosa, S. (2004): Literatura digital: el paradigma hipertextual, Cáceres: Universidad de Extremadura.

Palomo, M. B. (2005): “Estructura editorial. Diseño, navegación y usabilidad”, en R. Salaverría (coord.): Cibermedios. El impacto de internet en los medios de comunicación en España. Sevilla: Comunicación Social, 186-222.

Parodi, J. (2010): "Multisemiosis y lingüística de corpus: artefactos (multi)semióticos en los textos de seis disciplinas en el corpus PUCV-2010, Revista de Lingüística Teórica y Aplicada, 48 (2), II Sem., 33-70. [En línea]. Disponible en: http://www.scielo.cl/scielo. php?pid=S0718-48832010000200003\&script=sci_arttext]

Salaverría, R. (2006): “Técnicas de redacción ciberperiodística”, en R. Salaverría: Redacción periodística en Internet. Pamplona: Universidad de Navarra, 67-139.

Salaverría, R.; Sancho, F. (2007): Diseño periodístico en internet. Donostia-San Sebastián: Editorial de la Universidad del País Vasco.

Serafini, F. y Clausen, J. (2012): “Typography as Semiotic Resource”, Journal of Visual Literacy, 31(2) [En línea]. Disponible en: http:/www.frankserafini.com/publications/serafini-typography.pdf

Steen, M. (2009): "Extensión, formato de párrafo y separaciones", en M. Tascón (2009): Escribir en internet. Guía para los nuevos medios y las redes sociales. Barcelona: Galaxia Gutemberg. Círculo de lectores, 298-299.

Tascón, M. (dir.) (2012): Escribir en internet. Guía para los nuevos medios y las redes sociales. Barcelona: Galaxia Gutemberg. Círculo de lectores.

Yúfera, I., García, M. Á. y Polanco, F (2014): "El léxico jurídico en el periodismo digital: mecanismos de clarificación”, Lingüística Española Actual, XXXV/2, 181-208.

Van Dijk, T. (1988): La noticia como discurso. Comprensión, estructura y producción de la información. Barcelona: Paidós Comunicación, 1990.

Van Leeuwen, T. (2005a): “Typographic meaning”, Visual Communication, 4 (2). [En línea]. Disponible en: http://vcj.sagepub.com/content/4/2/137.extract

Van Leeuwen, T. (2005b): Introducing Social Semiotics. Routledge: London \& New York.

Van Leeuwen, T. (2006): "Towards a semiotics of typografy", Information Design Journal 14(2), 139-155. 